\title{
Generating and Comparing Aggregate Variables for Use Across Datasets in Multilevel Analysis
}

James Chowhan

McMaster University, Ontario, Canada, chowhan@mcmaster.ca

Laura Duncan

McMaster University, Ontario, Canada, duncanlj@mcmaster.ca

Follow this and additional works at: http://digitalcommons.wayne.edu/jmasm

Part of the Applied Statistics Commons, Social and Behavioral Sciences Commons, and the Statistical Theory Commons

\section{Recommended Citation}

Chowhan, James and Duncan, Laura (2009) "Generating and Comparing Aggregate Variables for Use Across Datasets in Multilevel Analysis," Journal of Modern Applied Statistical Methods: Vol. 8 : Iss. 2 , Article 29.

DOI: $10.22237 /$ jmasm/1257035280

Available at: http://digitalcommons.wayne.edu/jmasm/vol8/iss2/29 


\title{
Generating and Comparing Aggregate Variables for Use Across Datasets in Multilevel Analysis
}

\author{
James Chowhan Laura Duncan \\ McMaster University, \\ Ontario, Canada
}

This article examines the creation of contextual aggregate variables from one dataset for use with another dataset in multilevel analysis. The process of generating aggregate variables and methods of assessing the validity of the constructed aggregates are presented, together with the difficulties that this approach presents.

Key words: Aggregate variables, contextual variables, multilevel analysis.

Introduction

Contextual effects influence individual outcomes and behaviors. The importance of including community level variables has been gaining ground in the social sciences. Despite their popularity and the presence of theory corroborating the existence of contextual effects, proper measurement and selection of contextual variables continues to challenge researchers. Furthermore, researchers often face the additional difficulty presented by surveys that are not designed to contain contextual information at the geographic area of interest. Even when data is available at the appropriate geographic level, a deficiency of individuals in each area may prohibit the calculation of reliable estimates in multilevel models and thus make it difficult to successfully model contextual effects. A suitable approach to address these difficulties might be to construct aggregate variables in one dataset that has sufficient sample size in the area of interest for use with other datasets.

James Chowhan is a Ph.D. Student in the DeGroote School of Business. Email him at: chowhan@mcmaster.ca. Laura Duncan is a Research Coordinator in Psychiatry and Behavioural Neurosciences in the Offord Centre for Child Studies. Email her at: duncanlj@mcmaster.ca.
Conducting multilevel analyses requires contextual information at the level of interest, for example, family, household, neighborhood, province or country. Datasets are selected by researchers based on their ability to provide answers to research questions and the presence of key variables of interest at the level of interest. In many cases, datasets do not contain the contextual information at the required level for a multilevel analysis. In such cases, researchers could turn to another dataset to construct the desired measure and match this information, using geographical or other identifiers, to their original dataset.

Despite the apparent simplicity of this approach, the issue of checking aggregate variables must be addressed. If possible, the aggregate variables should be checked in some way to assess their validity (i.e., do they measure what they are supposed to measure?). One possible way of checking aggregate variables for validity is presented here, together with problems encountered during the process. These are presented as a means of highlighting some of the hidden complexities of creating aggregate variables that researchers should take into consideration when using this approach.

\section{Methodology}

The Survey of Labor and Income Dynamics (SLID) is a longitudinal survey on labor market activity and income. The survey follows individuals with yearly questionnaires 


\section{AGGREGATE VARIABLES FOR DATASETS IN MULTILEVEL ANALYSIS}

administered for six consecutive years, with a new wave starting every three years since the survey's 1993 initiation. The SLID contains variables that may be used to construct numerous interesting and relevant Economic Region (ER) level variables; thus, researchers could use the following procedures to construct ER level variables of their own choosing. For this example ten aggregate variables on employment and education were constructed; these variables were selected for their potential value to researchers for use in conjunction with other datasets. Table 1 contains the variable names, definitions and the original SLID variables from which they were constructed.

\section{Creation of an Analytic SLID Dataset}

First, the variables that were used to create the aggregates (shown in Table 1), were extracted from the SLID together with the appropriate cross-sectional weights and individual and geographical identifiers for each survey year using the SLIDret program. SLID identifies ERs by two separate variables: erres25 and xerres25. The explanation for the presence of two identifiers instead of one is that Statistics Canada amended their ER identification codes in 1999, thus, the SLID contains two sets of ER identification codes. One code refers to the 1991 Census boundaries for all survey years of the SLID (xerres25), and the other refers to the 1991 Census boundaries up to 1999 and to the amended 1999 Census boundaries in subsequent years (erres25). Researchers must decide upon the most appropriate variable to use in any particular research scenario. This will often be determined by the geographical code used in the dataset in which the constructed aggregate variables will be used.

Table 1: Defining Variables of Interest

\begin{tabular}{|c|c|c|}
\hline Variable Name & Definition & SLID Variables \\
\hline non-employee & $\begin{array}{c}\text { Proportion of total labor force self } \\
\text { employed }\end{array}$ & clwrkr1 \\
\hline non-employee_f & $\begin{array}{l}\text { Proportion of female labor force self } \\
\text { employed }\end{array}$ & clwrkr1 \\
\hline pct_mgt & $\begin{array}{l}\text { Proportion of occupations perceived to } \\
\text { be managerial }\end{array}$ & manag1 \\
\hline pct_mgt_f & $\begin{array}{c}\text { Proportion of female occupations } \\
\text { perceived to be managerial }\end{array}$ & manag1 \\
\hline less_hs & $\begin{array}{l}\text { Proportion of individuals with less } \\
\text { than a high school education }\end{array}$ & hlev2g18 \\
\hline hs & $\begin{array}{l}\text { Proportion of individuals with at least } \\
\text { a high school education }\end{array}$ & hlev2g18 \\
\hline non_univ_ps & $\begin{array}{l}\text { Proportion of individuals with a non- } \\
\text { university post-secondary certificate }\end{array}$ & hlev2g18 \\
\hline uni_ps & $\begin{array}{l}\text { Proportion of individuals with a } \\
\text { university post-secondary certificate }\end{array}$ & hlev2g18 \\
\hline ps & $\begin{array}{l}\text { Proportion of individuals with a post- } \\
\text { secondary certificate }\end{array}$ & hlev2g18 \\
\hline $\operatorname{ps}(\mathrm{f})$ & $\begin{array}{l}\text { Proportion of females with a post- } \\
\text { secondary certificate }\end{array}$ & hlev2g18 \\
\hline
\end{tabular}




\section{CHOWHAN \& DUNCAN}

This article compares the constructed aggregate variables and both the 1996 and 2001 Census profile data. Because the 1996 Census profile data uses the pre-1999 Census boundaries, the xerres 25 variable was used to calculate the 1996 SLID ER level estimates. Similarly, because the 2001 Census profile data uses the post-1999 Census boundaries, the erres 25 variable was used for the 2001 SLID ER level estimates.

\section{Construction of Aggregate SLID Variables}

After creating a SLID dataset, the ER aggregate variables can be constructed. Ten aggregate SLID variables were constructed, seven for the entire population and three for the female population only. The approach was to create a count of individuals in each ER possessing the characteristics of interest and to use this count to construct weighted proportions aggregated at the ER level that could then be exported for use with other datasets.

For each characteristic of interest individuals with that characteristic are dummy coded as 1 . This results in dummy variables for individuals aged 15 to 69 who are self employed, individuals aged 15 to 69 whose occupations are perceived as managerial, individuals aged 16 and over who have less than a high school education, individuals aged 16 and over who have at least a high school education, individuals aged 16 and over who have a nonuniversity post-secondary certificate, individuals aged 16 and over who have a university postsecondary certificate, and individuals aged 16 and over who have a post-secondary certificate (university or non-university). There was also a dummy variable for gender so dummy variables could be created for females, for females aged 15 to 69 who are self employed, females aged 15 to 69 whose occupations are perceived as managerial, and females aged 16 and over who have a post-secondary certificate (university or non-university).

\section{Aggregating SLID to the ER Level}

After creating SLID dummy variables; the final step was to aggregate these variables. In all cases these aggregates will be proportions for each ER created by aggregating up to the ER level. Because the SLID produces an annual cross-section of individuals it is also necessary to aggregate to the ER level by survey year in order to obtain an accurate estimate of area level characteristics for each year. Taking the mean of a dummy variable is one way to calculate the proportion of individuals with a certain characteristic. Hence, proportions for each ER are calculated by collapsing the dummy variables to their mean for each ER level and for each survey year. These proportions are weighted using the cross-sectional weight. The resulting aggregate variables represent proportions of individuals in ERs with the characteristics of interest outlined.

Once created, aggregates are ready for use; however, it is highly recommend that a check be carried out to assess their validity as aggregate measures. This is accomplished in the following example by comparing the provincial and national population totals followed by the basic gender and age characteristics of the samples. The logic being that, if the population totals are similar and sample characteristics are similar across these demographics, there is some reason to assume that they will be similar in other ways. It is not guaranteed that this is actually the case, however.

As an additional check, similar education and employment aggregates constructed using the Census profile data from 1996 and 2001 were compared as well. (This will not be an option readily available to researchers if one of the main reasons for going to another dataset is that the variables of interest are not available in the Census profile data.) These comparisons are recommended because they will alert a researcher to oddities about the variables or dataset used and to inconsistencies that may require investigation.

To assess the validity of the aggregate SLID variables constructed, a comparison was made to the 1996 and 2001 Census. The Census is, by design, the most accurate and representative approximation of true population parameters. In order for the SLID aggregates to be useful they should reflect true population parameters. It may be argued that using the Census to verify how closely the SLID data and constructed aggregates reflect the true population is the most suitable method of comparison available. As the SLID weighting is 


\section{AGGREGATE VARIABLES FOR DATASETS IN MULTILEVEL ANALYSIS}

calibrated on Census population totals, it is expected that estimates will match well. The following is a step-by-step guide to comparing aggregate variables.

\section{Choose a Method of Comparison}

Two methods of comparison were used in this example. The first involved simply calculating and comparing provincial and national population totals for both SLID datasets for 1996 and 2001. If no similarity existed at this level it would not be sensible to continue with the comparison and the validity of the aggregate variables would be questionable. The second method of comparison used confidence intervals as a means of statistically assessing how close the estimates match. This requires similarly defined variables to be created using Census profile data so that aggregates are created from the SLID and the Census profile data at the ER level. Confidence intervals (assuming a Normal distribution) can be created around the SLID estimates and observations made as to whether the population estimates from the Census fall within these confidence intervals for each ER. The confidence level chosen for this example is $95 \%$ but researchers can choose any level they think is suitable. A high number of matches show the SLID estimates are a good match to true population parameters.

Choose and Generate Demographic Variables and Confidence Intervals

For the provincial and national population totals, weighted sums were calculated in STATA broken out by province. At the ER level, two characteristics were chosen for comparison: gender and age. Twenty-one age and gender breakouts by ER were calculated using the SLID data for 1996 and 2001. In addition to the proportion of females, age breakouts for the whole population and for females only are generated using different age intervals. Using STATA, 95\% confidence intervals were created for each SLID estimate.

Recreate Aggregate Variables Using Census Profile Data

Because the Census profile data does not contain ER identification codes it is first necessary to merge the Census data with the
Postal Code Conversion File (PCCF), matching the data by Enumeration Area (EA) for 1996 and Dissemination Area (DA) for 2001. Enumeration areas (EA) in the 1996 Census and Dissemination areas (DA) in the 2001 Census are smaller geographical areas making up various larger Statistics Canada geographical areas, including ERs. The 1999 change in Census boundaries lead to a name and definition change from EA to DA (for more information on using the PCCF and the change from EA to DA see Gonthier, et al., 2006).

For 1996 the EA code is an eight-digit code constructed from provincial, federal and EA identifiers. The provincial code composes the first two digits; the federal code the following three and the EA code the final three. To construct the eight-digit EA code from its composite parts the provincial code is multiplied by $1,000,000$ and the federal code is multiplied by 1,000 , and these numbers are added to the EA code. The Census data is then merged with the 1996 PCCF file using this eight-digit EA identifier.

For 2001 the DA code is an eight-digit code constructed from provincial, census division and DA identifiers. The provincial code composes the first two digits, the census division code the following two and the DA code the final four. The eight-digit DA code for 2001 is created the same way as the EA code for 1996. Merging results in each record being assigned an ER identification code. Once again, to ensure the production of accurate estimates, data is aggregated to the ER level by first creating a sum of all individuals within ERs with the characteristics of interest. This ensures accurately weighted estimates reflecting the numbers of individuals in ERs. After these sums are created for each ER proportions are then calculated that correspond to the ten aggregate variables created in the SLID. Table 2 shows the variable names and the 1996 and 2001 Census variables from which they were constructed.

\section{Compare SLID and Census Profile Data} Estimates

With the SLID education and employment aggregates, population totals, demographic variables, confidence intervals for these estimates for 1996 and 2001 and similar 


\section{CHOWHAN \& DUNCAN}

Table 2: Concordance between 1996 and 2001 Census Variables

\begin{tabular}{|c|c|c|c|}
\hline Variable Name & Definition & $\begin{array}{c}1996 \text { Census Variable } \\
\text { Range Used }\end{array}$ & $\begin{array}{c}2001 \text { Census Variable } \\
\text { Range Used }\end{array}$ \\
\hline non_employee & $\begin{array}{c}\text { Proportion of total labor force self } \\
\text { employed }\end{array}$ & v1211-v1222 & v949-v960 \\
\hline non_employee_f & $\begin{array}{c}\text { Proportion of female labor force self } \\
\text { employed }\end{array}$ & v1235-v1246 & v973-v984 \\
\hline pct_mgt & $\begin{array}{c}\text { Proportion of occupations perceived } \\
\text { to be managerial }\end{array}$ & v1031-v1090 & v985-v1044 \\
\hline pct_mgt_f & $\begin{array}{c}\text { Proportion of female occupations } \\
\text { perceived to be managerial }\end{array}$ & v1151-v1210 & v1105-v1164 \\
\hline less_hs & $\begin{array}{c}\text { Proportion of individuals with less } \\
\text { than a high school education }\end{array}$ & v1338-v1351 & v1382-v1395 \\
\hline hs & $\begin{array}{c}\text { Proportion of individuals with at } \\
\text { least a high school education }\end{array}$ & v1338-v1351 & v1382-v1395 \\
\hline non_univ_ps & $\begin{array}{c}\text { Proportion of individuals with a non- } \\
\text { university post-secondary certificate }\end{array}$ & v1338-v1351 & v1382-v1395 \\
\hline uni_ps & $\begin{array}{c}\text { Proportion of individuals with a } \\
\text { university post-secondary certificate }\end{array}$ & v1338-v1351 & v1382-v1395 \\
\hline ps & $\begin{array}{c}\text { Proportion of individuals with a } \\
\text { post-secondary certificate }\end{array}$ & v1352-v1375 & v1358-v1381 \\
\hline ps_f & $\begin{array}{c}\text { Proportion of females with a post- } \\
\text { secondary certificate }\end{array}$ & v1352-v1375 & v1358-v1381 \\
\hline
\end{tabular}

variables recreated using Census profile data from 1996 and 2001, the comparison was carried out. First, weighted provincial and national population totals were compared by year and by province; results are shown in Tables $3 \mathrm{a}$ and $3 \mathrm{~b}$.

It is important to note that some variation in the totals is to be expected due to rounding error in the Census. In both tables it was expected that column 1 and 2 add up to column 3. In 1996, there was a difference of 685 and in 2001 there is a difference of 235 . These differences are likely due to rounding error. It would also be expected that column 4 and column 6 would be similar and that column 5 would be less than both of these. In 1996 the total population is SLID is 271,963 more than the Census total population and in 2001, the total population in the SLID is $1,828,145$ below the Census total population: no obvious reason exists to explain this. Even with the minor disparity, population totals in the SLID are close enough to the Census to conclude that the data matches reasonably well.

Second, basic demographics were compared by year and by ER in order to determine the number of Census profile estimates that would fall within the 95\% confidence intervals generated around the SLID estimates. Each Census profile estimate falling within the confidence interval was called a match. Table 4 shows the percentage of matches across 66 ERs in 1996 and 73 ERs in 2001.

The proportion of females in the population variable matched perfectly and the age breakouts had a high, but not perfect, percentage of matches. The only variables with suspiciously low numbers of matches were the percentage of individuals aged 15 to 19 and the percentage of females aged 15 to 19 . The age breakouts for individuals and females aged 15 to 25 and 20 to 24 showed much better matching. This suggests that the discrepancy is occurring at 


\section{AGGREGATE VARIABLES FOR DATASETS IN MULTILEVEL ANALYSIS}

the lower end of the age spectrum in the 15 to 19 age range.

Based on observations of similarities in the population totals, gender and age characteristics across the SLID and Census profile data samples, it may be suggested that the SLID and the Census profile data will also be similar across other characteristics, in this case education and employment. To test this, the constructed aggregates were checked for validity in a similar manner. Again, 95\% confidence intervals (assuming a Normal distribution) were created around the SLID estimates and observations were made as to whether the population estimates from the Census fell within these confidence intervals for each ER. Table 5 shows the percentage of matches across 66 ERs in 1996 and 73 in 2001.

Given the excellent age and gender match of the data, the low number of matches for the constructed aggregate variables is surprising. Without a clear explanation as to why the variables do not match, the constructed aggregates cannot be trusted as representative and should not be used. However, if explanations can be found for the low matching then the aggregates may be of some use. An investigation of the data and variable definitions was carried out to identify possible causes for the low number of matches.

Investigation of the data and examination of the documentation highlighted several limitations with the variables chosen for use in both the Census profile data and the SLID. These limitations are very likely the cause of the low number of matches across the aggregate variables. First, the internal consistency of the constructed estimates was investigated. In particular, confirmation was required that the total populations being used on the SLID and in the Census Profile data as the denominator in the proportions calculations were in fact the sum of their composite parts. In both the SLID and the Census Profile data, age and education populations were verified. A check was made of the proportions of individuals aged under 25,25 to 49,50 to 74 and 75 ; these proportions should total 1 as this range of ages encompasses all possible ages in the population. The same check was carried out for the female proportions and for the proportions of individuals aged under 25,25 to 49,50 to 64 and

Table 3a: Provincial and National Totals for SLID and Census Profile Data, 1996

\begin{tabular}{|c|c|c|c|c|c|c|}
\hline 1996 & \multicolumn{5}{|c|}{ Census } & SLID \\
\hline Province & $\begin{array}{c}1 . \text { Male } \\
\text { Subtotal }\end{array}$ & $\begin{array}{c}2 . \text { Female } \\
\text { Subtotal }\end{array}$ & $\begin{array}{c}\text { 3. Total } \\
\text { Population }\end{array}$ & $\begin{array}{c}\text { 4. Total } \\
\text { Population 15+ }\end{array}$ & $\begin{array}{c}\text { 5. Total Labor } \\
\text { Force 15+ }\end{array}$ & $\begin{array}{c}\text { 6. Total } \\
\text { Population 15+ }\end{array}$ \\
\hline 10 & 271,740 & 278,575 & 550,420 & 435,985 & 245,165 & 423,747 \\
\hline 11 & 65,990 & 68,450 & 134,440 & 103,580 & 70,695 & 100,100 \\
\hline 12 & 441,490 & 466,175 & 907,635 & 718,015 & 438,010 & 669,414 \\
\hline 13 & 362,490 & 374,665 & 737,255 & 583,550 & 363,055 & 556,031 \\
\hline 24 & $3,318,800$ & $3,462,665$ & $6,781,570$ & $5,382,325$ & $3,357,080$ & $5,394,101$ \\
\hline 35 & $4,794,345$ & $5,011,300$ & $9,805,685$ & $7,669,850$ & $5,084,190$ & $7,848,826$ \\
\hline 46 & 492,640 & 509,980 & $1,002,730$ & 769,900 & 511,145 & 782,124 \\
\hline 47 & 450,690 & 461,550 & 912,085 & 689,015 & 463,360 & 687,939 \\
\hline 48 & $1,225,800$ & $1,227,510$ & $2,453,330$ & $1,864,640$ & $1,348,880$ & $1,895,376$ \\
\hline 59 & $1,706,985$ & $1,751,340$ & $3,458,715$ & $2,743,105$ & $1,819,185$ & $2,874,269$ \\
\hline Total & $13,130,970$ & $13,612,210$ & $26,743,865$ & $20,959,965$ & $13,700,765$ & $21,231,928$ \\
\hline
\end{tabular}




\section{CHOWHAN \& DUNCAN}

Table 3b: Provincial and National Totals for SLID and Census Profile Data, 2001

\begin{tabular}{|c|c|c|c|c|c|c|}
\hline 2001 & \multicolumn{5}{|c|}{ Census } & SLID \\
\hline Province & $\begin{array}{c}1 . \text { Male } \\
\text { Subtotal }\end{array}$ & $\begin{array}{c}2 . \text { Female } \\
\text { Subtotal }\end{array}$ & $\begin{array}{c}\text { 3. Total } \\
\text { Population }\end{array}$ & $\begin{array}{c}\text { 4. Total } \\
\text { Population 15+ }\end{array}$ & $\begin{array}{c}\text { 5. Total Labor } \\
\text { Force 15+ }\end{array}$ & $\begin{array}{c}6 . \text { Total } \\
\text { Population 15+ }\end{array}$ \\
\hline 10 & 249,805 & 260,815 & 510,545 & 422,170 & 240,600 & 404,336 \\
\hline 11 & 65,450 & 69,145 & 134,530 & 107,940 & 73,570 & 98,323 \\
\hline 12 & 437,335 & 466,330 & 903,505 & 739,060 & 450,075 & 681,910 \\
\hline 13 & 355,380 & 371,485 & 726,990 & 597,500 & 370,920 & 548,849 \\
\hline 24 & $3,521,985$ & $3,689,680$ & $7,212,255$ & $5,923,010$ & $3,734,615$ & $5,270,975$ \\
\hline 35 & $5,458,005$ & $5,701,920$ & $11,159,880$ & $8,972,500$ & $5,950,800$ & $8,426,920$ \\
\hline 46 & 547,455 & 567,110 & $1,114,400$ & 881,395 & 582,590 & 796,246 \\
\hline 47 & 478,785 & 494,380 & 973,075 & 766,390 & 509,670 & 691,965 \\
\hline 48 & $1,470,895$ & $1,473,690$ & $2,944,620$ & $2,334,465$ & $1,678,965$ & $2,193,306$ \\
\hline 59 & $1,908,975$ & $1,978,245$ & $3,887,305$ & $3,183,715$ & $2,046,190$ & $2,994,323$ \\
\hline Total & $14,494,070$ & $15,072,800$ & $29,567,105$ & $23,928,145$ & $15,637,995$ & $22,100,000$ \\
\hline
\end{tabular}

Table 4: Comparison of SLID and Census Profile Aggregate Estimates for Gender and Age Variables

\begin{tabular}{|c|c|c|c|}
\hline \multirow{2}{*}{ Variable Name } & \multirow{2}{*}{ Variable Definition } & 1996 & 2001 \\
\hline & & $\%$ of Matches & $\%$ of Matches \\
\hline female & $\%$ population that is female & 100 & 97 \\
\hline pct_15to25 & $\%$ population aged 15 to 25 & 71 & 70 \\
\hline pct 25 to 49 & $\%$ population aged 25 to 49 & 79 & 78 \\
\hline pct_50to74 & $\%$ population aged 50 to 74 & 70 & 84 \\
\hline pct_75over & $\%$ population aged $75 \&$ over & 62 & 78 \\
\hline pct_50to64 & $\%$ population aged 50 to 64 & 68 & 79 \\
\hline pct_65over & $\%$ population aged $65 \&$ over & 70 & 74 \\
\hline pct_15to19 & $\%$ population aged 15 to 19 & 44 & 52 \\
\hline pct_20to24 & $\%$ population aged 20 to 24 & 80 & 86 \\
\hline pct 40 to 44 & $\%$ population aged 40 to 44 & 90 & 88 \\
\hline pct_75to79 & $\%$ population aged 75 to 79 & 74 & 89 \\
\hline pct_15to25_f & $\%$ female population aged 15 to 25 & 68 & 74 \\
\hline pct 25 to $49 \mathrm{f}$ & $\%$ female population aged 25 to 49 & 85 & 88 \\
\hline pct_50to74_f & $\%$ female population aged 50 to 74 & 76 & 86 \\
\hline pct_75over_f & $\%$ female population aged $75 \&$ over & 73 & 88 \\
\hline pct_50to64 f & $\%$ female population aged 50 to 64 & 79 & 86 \\
\hline pct_65over_f & $\%$ female population aged $65 \&$ over & 77 & 82 \\
\hline pct_15to19_f & $\%$ female population aged 15 to 19 & 70 & 66 \\
\hline pct_20to24_f & $\%$ female population aged 20 to 24 & 80 & 92 \\
\hline pct_40to44_f & $\%$ female population aged 40 to 44 & 85 & 92 \\
\hline pct_75to79_f & $\%$ female population aged 75 to 79 & 83 & 92 \\
\hline
\end{tabular}


AGGREGATE VARIABLES FOR DATASETS IN MULTILEVEL ANALYSIS

Table 5: Comparison of SLID and Census Profile Aggregate Estimates for Employment and Education Variables

\begin{tabular}{|c|c|c|c|}
\hline \multirow{2}{*}{ Variable Name } & \multirow{2}{*}{ Variable Description } & \multicolumn{2}{|c|}{$\%$ of Matches } \\
\hline & & 1996 & 2001 \\
\hline non_employee & Proportion of total labor force self employed & 44 & 55 \\
\hline non_employee_f & Proportion of female labor force self employed & 61 & 67 \\
\hline pct_mgt & $\begin{array}{c}\text { Proportion of occupations perceived to be } \\
\text { managerial }\end{array}$ & 20 & 8 \\
\hline pct_mgt_f & $\begin{array}{l}\text { Proportion of female occupations perceived to } \\
\text { be managerial }\end{array}$ & 30 & 22 \\
\hline less_hs & $\begin{array}{l}\text { Proportion of individuals with less than a high } \\
\text { school education }\end{array}$ & 33 & 51 \\
\hline hs & $\begin{array}{l}\text { Proportion of individuals with at least a high } \\
\text { school education }\end{array}$ & 2 & 0 \\
\hline non_univ_ps & $\begin{array}{l}\text { Proportion of individuals with a non-university } \\
\text { post-secondary certificate }\end{array}$ & 42 & 79 \\
\hline univ_ps & $\begin{array}{c}\text { Proportion of individuals with a university } \\
\text { post-secondary certificate }\end{array}$ & 35 & 60 \\
\hline ps & $\begin{array}{l}\text { Proportion of individuals with a post- } \\
\text { secondary certificate }\end{array}$ & 74 & 59 \\
\hline ps_f & $\begin{array}{l}\text { Proportion of females with a post-secondary } \\
\text { certificate }\end{array}$ & 88 & 85 \\
\hline
\end{tabular}

65 and over. It was found that the 15 to 19 age category produced low numbers of matches. Verification was made that the difference between the proportion of individuals aged under 25 and the proportion of individuals aged 15 to 19 added to the proportion of individuals aged 20 to 24 equals 0 . The same verification was made for the female proportions. The results were either extremely close or exactly 0 or 1 (See Appendix 1 for details).

Additional checks were carried out for the education variables in the Census Profile data for both 1996 and 2001. The difference between the proportion of individuals with postsecondary certificates and the proportion of individuals with university certificates added to the proportion of individuals with non-university certificates was checked with the expectation that, if accurate, they should equal 0 . Results were either 0 or less than 0.0001 above or below 0 . The proportion of individuals with less than a high school education were added to individuals with at least a high school education with the expectation that they would equal 1 . This was not the case: most totals ranged from 0.4 to 0.6 . Referring to the documentation and exploring the data illuminated the reason. The Total population 15 years and over by highest level of schooling is a poorly defined population. The Census Profile data contains numerous population totals broken out by different characteristics. For example, the education variables include 'Total population 15 years and over by highest level of schooling', the marital status variables include 'Total population 15 years and over by marital status' and the labor force variables include 'Total population 15 years and over by labor force activity'. It was expected that summing together the number of individuals aged 15 years and over using the age breakouts in the Census Profile data would include the same population as these 'Total population 15 years and over by...' variables. This was checked for the 'Total population 15 


\section{CHOWHAN \& DUNCAN}

years and over by highest level of schooling' variable. The difference between these two totals was more than can be explained by rounding error in the Census Profile data. Checking this variable against other variables that call themselves 'Total population 15 years and over by...' a sizeable and apparently unexplainable difference was found. Another drawback with the 2001 education aggregate variables is that in the 2001 Census Profile data education data is supplied for individuals aged 20 and over (Statistics Canada, 1999). By contrast, SLID education data was available for individuals aged 15 and over. This, added to the other problems described, provides the reason why the education aggregate variables do not match well.

Having identified an explanation for the low matching across education variables, similar explanations were sought for the employment variables. Three main limitations in both the Census Profiles and SLID documentation regarding ambiguous definitions of populations and variables were found that could explain the low number of matches across the employment variables. First, there was some ambiguity over the definition of the labor force. SLID defines the labor force as persons aged 16 to 69 who were employed during the survey reference period. Therefore, the employment variables used in the construction of the aggregate variables only refers to these individuals. The Census Profile data on the other hand defines the labor force as employed individuals aged 15 and over. Although this may cause some disparity, it is unlikely to be the only cause of the low number of matches. Further investigation revealed a more severe limitation regarding the classification of individual labor force status (Statistics Canada, 1997; Statistics Canada, 1999).

One of the strengths of the SLID as a longitudinal survey is that it asks for information on every job an individual has held during the reference year, rather than focusing on the job at the time of the survey. Regarding class of worker (paid worker, employee, self-employed, etc.) individuals can, therefore, hold several statuses, in addition, they are asked to report their status for each month so that they have 12 statuses over the year. By contrast, the Census Profile data only reports the class of worker for individuals at the time the Census is carried out. For the construction of the non_employee aggregate variable, it was necessary that individuals only fall into one class of worker category. However, the SLID uses the main job concept to categorize individuals into the class of worker variable clwrkr1. Main job is typically the job with the longest duration, greatest number of hours worked over the year, and most usual hours worked in a given month (Statistics Canada, 1997; Statistics Canada, 2007). Thus, the difference in the reference periods of the samples and the SLID's focus on main job is a possible explanation for lower matching rates.

The Census Profile data has its own ambiguities around the class of worker variable. In the Census Profile data on class of worker there is a category defined as Class of workerNot Applicable (Statistics Canada, 1999). The documentation does not explain who this group consists of or what characteristics of individuals in this category make class of worker not applicable to them. In an effort to take this into account, the aggregate variable of non-employee was constructed using an all classes of worker variable as the denominator (a variable that does not include the class of worker-not applicable individuals). This was used in place of the variable total labor force 15 years and over by class of worker, which did include those individuals. Although this avoids using unclear population definitions as a denominator, it does not help explain where that category of individuals should be included most accurately in the class of worker categorization. These problems may explain why the non_employee variables are not matching well.

Finally, there was a difference in the definition of the Census Profile data and SLID managerial occupation variables that may render them incomparable. In the Census Profile data, individuals are asked to explain the type of job they have and their main responsibilities, and from this information they are coded into occupation classifications. This classification includes a section on management occupations that was used to produce the proportion of individuals with occupations perceived to be managerial variable (Statistics Canada, 1999). In the SLID, on the other hand, individuals are asked if they perceive their job to be managerial 


\section{AGGREGATE VARIABLES FOR DATASETS IN MULTILEVEL ANALYSIS}

(Statistics Canada, 1997). The self-identification involved here suggests that this variable is likely to be largely inconsistent: what defines a job as managerial is not clearly defined. Individuals may identify themselves as having a managerial job when in fact they do not. This could explain why the pct_mgt variable does not show a high number of matches.

\section{Conclusion}

The investigations and results are outlined here as a precaution to researchers wishing to create aggregate variables or use the SLID aggregate variables created in this study. The construction and comparison of aggregate variables should not be undertaken without caution. Despite their limitation, it is hoped that the constructed SLID aggregates could be of some use to researchers. The following points serve as a set of cautions to those wishing to use this approach based on difficulties that might be encountered in aggregate variable construction and comparison.

\section{Internal Consistency}

When constructing aggregate variables it is important that the variables are internally coherent. For example, imagine creating two aggregate education variables at the EA level; one is the proportion of individuals with less than a high school education, the other is the proportion of individuals with at least a high school education. If a researcher added the two proportions together across all EAs all totals should equal 1, if it does not, further investigation would be required to uncover reasons why.

\section{Target Population}

When creating and comparing aggregate variables it is important to know the target population of the variable. Some variables apply to individuals over a certain age, some apply to individuals who only answered positively to survey questions, and some apply to all respondents. This becomes more important if researchers wish to check the validity of their constructed aggregates by comparing the sample characteristics with the Census profile data characteristics. If constructing proportions of individuals with certain characteristics, it is important that the denominator be the same in both variables. The Census profile data documentation clearly defines its target population for each variable but it can be unclear how individuals were included. For example, in the 1996 Census profile data the 'Total population 15 years and over by highest level of schooling' was not the same as 'All individuals aged 15 years and over'. In some cases, the target populations for the same variable in the 1996 and 2001 Census profile data were different. For example, in the 1996 Census profile data, the education data was available for individuals aged 15 and over; and in the 2001 Census profile data, it was supplied for individuals aged 20 and over (Statistics Canada, 1999).

\section{Definitions}

It is important to understand how variables are defined in order to construct useful aggregate variables that are as accurate as possible. What a researcher may consider to be a standard classification may in fact be different across different datasets. In the example used in this article, it was found that the definition of labor force was not clear. In SLID, labor force is defined as persons aged 16 to 69 who were employed during the survey reference period. In the Census profile data, the labor force is defined as employed individuals aged 15 and over. This difference made comparing the Census profile and SLID aggregate employment variables inappropriate. Variable definitions may also have unexplained ambiguities that must be taken into account. For example, in the Census profile data there were ambiguities with the class of worker variable, which made comparison difficult.

\section{Survey Design}

The way in which surveys are designed can make constructing and comparing aggregate variables problematic. One of the strengths of the SLID as a longitudinal survey is that it asks for information on every job an individual has held during the reference year rather than focusing on the job at the time the survey is carried out. The result is that many records may exist for one individual. By contrast, the Census profile data holds one record per individual. Researchers must be clear on the survey design 


\section{CHOWHAN \& DUNCAN}

and number of records per individual. If several records exist for each individual, some rationale must be used to select the most suitable record.

\section{Classification}

It is important to understand how variables have been coded into categories and whether individuals self-identify for certain classifications. This has implications for category definitions and how comparable they are across datasets. In the example provided, a difference was identified between the Census profile data and SLID in how managerial occupations are defined. The difference between coding by self-identification and coding by an external classifier is an important one that could lead to inconsistent definitions.

This article outlined the importance of aggregate level variables for use in multilevel analysis and introduced the idea of generating aggregate level variables in one dataset for use across other datasets. Generating and comparing aggregate variables was described using an example generating employment and education aggregate variables in the SLID for 1996 and 2001 cross-sectional samples at the ER Level and comparing them to similar estimates constructed using the 1996 and 2001 Census profile data.
The difficulties encountered resulted in a set of cautions for researchers wishing to use this approach. As a whole, this article may serve as a guide to researchers in the generation and comparison of these or similar aggregate variables and also emphasizes the precautions that must be taken when using this approach.

\section{References}

Gonthier, D., Hotton, T., Cook, C., \& Wilkins, R. (2006). Merging area-level census data with survey data in statistics Canada research data centres. The Research Data Centres Information and Technical Bulletin, 3(1), 21-39.

Statistics Canada. 1997. Survey of labour and income dynamics: Microdata user's guide. Dynamics of Labour and Income. Catalogue No. 75M0001GPE. Ministry of Industry, Ottawa.

Statistics Canada. 1999. 1996 Census Dictionary, Final Edition Reference. Catalogue No. 92-351-UIE. Ministry of Industry, Ottawa.

Statistics Canada. 2007. Guide to the Labour Force Survey. Dynamics of Labour and Income. Labour Statistics Division. Catalogue No. 71543-GIE. Ministry of Industry, Ottawa.

Appendix

Tables A1 and A2 show the age and education verifications by ER for both the Census and the SLID for 1996 and 2001. The variable definitions are as follows:

\begin{tabular}{|ll|}
\hline SLIDage1: & 'pct_15to25' + 'pct_25to49' + 'pct_50to74' + 'pct_75over' \\
\hline SLIDage2: & 'pct_15to25' + 'pct_25to49' + 'pct_50to64' + 'pct_65over' \\
\hline SLIDage3: & Difference between 'pct_15to25' and ('pct_15to19' + 'pct_20to24') \\
\hline SLIDage4: & SLIDage1 for females \\
\hline SLIDage5: & SLIDage2 for females \\
\hline SLIDage6: & SLIDage3 for females \\
\hline Censage1: & 'pct_15to25' + 'pct_25to49' + 'pct_50to74' + 'pct_75over' \\
\hline Censage2: & 'pct_15to25' + 'pct_25to49' + 'pct_50to64' + 'pct_65over' \\
\hline Censage3: & Difference between 'pct_15to25' and ('pct_15to19' + 'pct_20to24') \\
\hline Censage4: & Censusage1 for females \\
\hline Censage5: & Censusage2 for females \\
\hline Censage6: & Censusage3 for females \\
\hline Censedu1: & 'Less than high school' + 'at least high school' \\
\hline Censedu2: & $\begin{array}{l}\text { Difference between 'postsecondary certificate' and 'university certificate' }+ \text { 'non- } \\
\text { university certificate' }\end{array}$ \\
\hline
\end{tabular}


AGGREGATE VARIABLES FOR DATASETS IN MULTILEVEL ANALYSIS

Table A1: 1996 Age and Education Verifications by ER for the Census and SLID

\begin{tabular}{|c|c|c|c|c|c|c|c|c|c|c|c|c|c|c|}
\hline xerres 25 & SLIDage1 & SLIDage2 & SLIDage3 & SLIDage4 & SLIDage5 & SLIDage6 & Censage1 & Censage2 & Censage 3 & Censage4 & Censage5 & Censage6 & Censedu1 & Censedu2 \\
\hline 1010 & 1 & 1 & 7.45E-09 & 1 & 1 & $0.00 \mathrm{E}+00$ & 1.0001 & 1.0001 & 0 & 0.9990 & 0.9990 & $-7.45 \mathrm{E}-09$ & $\begin{array}{l}0.4942 \\
\end{array}$ & -0.0006 \\
\hline 1020 & 1 & 1 & 0 & 1 & 1 & $7.45 \mathrm{E}-09$ & 1.0032 & 1.0032 & 0 & 1.0065 & 1.0065 & 0 & 0.7476 & $\begin{array}{l}-0.0015 \\
\end{array}$ \\
\hline 1030 & 1 & 1 & 7.45E-09 & 1 & 1 & 0 & 0.9990 & 0.9990 & $-7.45 \mathrm{E}-09$ & 1.0020 & 1.0020 & 0 & 0.6251 & -0.0002 \\
\hline 1040 & 1 & 1 & 7.45E-09 & 1 & 1 & 7.45E-09 & 1.0001 & 1.0001 & 7.45E-09 & 1.0031 & 1.0031 & 7.45E-09 & 0.6711 & -0.0010 \\
\hline 1110 & 1 & 1 & 0 & 1 & 1 & $0.00 E+00$ & 0.9982 & 0.9982 & $7.45 \mathrm{E}-09$ & 0.9957 & 0.9957 & $7.45 \mathrm{E}-09$ & 0.5573 & $\begin{array}{l}-0.0017 \\
\end{array}$ \\
\hline 1210 & 1 & 1 & 0 & 1 & 1 & 0 & 0.9990 & 0.9990 & 0 & 0.9980 & 0.9980 & $-7.45 \mathrm{E}-09$ & 0.5875 & $\begin{array}{l}-0.0005 \\
\end{array}$ \\
\hline 1220 & 1 & 1 & 0 & 1 & 1 & $0.00 E+00$ & 1.0028 & 1.0028 & 0 & 1.0051 & 1.0051 & 0 & 0.5713 & -0.0023 \\
\hline 1230 & 1 & 1 & $-7.45 \mathrm{E}-09$ & 1 & 1 & $7.45 \mathrm{E}-09$ & 1.0001 & 1.0001 & $-7.45 \mathrm{E}-09$ & 0.9991 & 0.9991 & 0 & 0.5520 & -0.0013 \\
\hline 1240 & 1 & 1 & 0 & 1 & 1 & $-3.73 \mathrm{E}-09$ & 1.0003 & 1.0003 & $-7.45 \mathrm{E}-09$ & 0.9996 & 0.9996 & $-7.45 \mathrm{E}-09$ & 0.6180 & -0.0014 \\
\hline 1250 & 1 & 1 & $-7.45 E-09$ & 1 & 1 & $7.45 \mathrm{E}-09$ & 1.0002 & 1.0002 & $-7.45 \mathrm{E}-09$ & 1.0001 & 1.0001 & $-7.45 \mathrm{E}-09$ & 0.4052 & -0.0018 \\
\hline 1310 & 1 & 1 & $7.45 \mathrm{E}-09$ & 1 & 1 & 0 & 1.0018 & 1.0018 & 0 & 1.0021 & 1.0021 & $-7.45 \mathrm{E}-09$ & 0.6512 & -0.0012 \\
\hline 1320 & 1 & 1 & 0 & 1 & 1 & $-3.73 \mathrm{E}-09$ & 0.9988 & 0.9988 & $7.45 \mathrm{E}-09$ & 0.9998 & 0.9998 & $-7.45 \mathrm{E}-09$ & 0.5567 & -0.0019 \\
\hline 1330 & 1 & 1 & 1.12E-08 & 1 & 1 & $0.00 E+00$ & 1.0014 & 1.0014 & 0 & 1.0009 & 1.0009 & $7.45 \mathrm{E}-09$ & 0.5584 & $\begin{array}{l}-0.0014 \\
\end{array}$ \\
\hline 1340 & 1 & 1 & 0 & 1 & 1 & 0 & 1.0012 & 1.0012 & $-7.45 \mathrm{E}-09$ & 1.0042 & 1.0042 & 0 & 0.5072 & -0.0008 \\
\hline 1350 & 0.9999999 & 1 & $7.45 \mathrm{E}-09$ & 1 & 1 & $7.45 \mathrm{E}-09$ & 0.9993 & 0.9993 & $-7.45 \mathrm{E}-09$ & 1.0001 & 1.0001 & $7.45 \mathrm{E}-09$ & 0.6550 & -0.0018 \\
\hline 2410 & 1 & 1 & 3.73E-09 & 1 & 1 & $0.00 \mathrm{E}+00$ & 1.0004 & 1.0004 & $-7.45 \mathrm{E}-09$ & 1.0035 & 1.0035 & $-7.45 \mathrm{E}-09$ & 0.6955 & -0.0021 \\
\hline 2415 & 1 & 1 & 0 & 1 & 1 & 0 & 1.0030 & 1.0030 & 0 & 1.0033 & 1.0033 & 0 & 0.6180 & -0.0018 \\
\hline 2420 & 1 & 1 & $7.45 \mathrm{E}-09$ & 1 & 1 & $-7.45 \mathrm{E}-09$ & 0.9993 & 0.9993 & 0 & 0.9988 & 0.9988 & $-7.45 \mathrm{E}-09$ & 0.4903 & -0.0013 \\
\hline 2425 & 1 & 1 & $-7.45 \mathrm{E}-09$ & 0.9999999 & 0.9999999 & 3.73E-09 & 1.0004 & 1.0004 & $-7.45 \mathrm{E}-09$ & 1.0009 & 1.0009 & 0 & 0.5995 & -0.0018 \\
\hline 2430 & 1 & 1 & $-7.45 \mathrm{E}-09$ & 1 & 1 & $-3.73 \mathrm{E}-09$ & 1.0011 & 1.0011 & 0 & 1.0032 & 1.0032 & 0 & 0.5755 & -0.0013 \\
\hline 2435 & 1 & 1 & $7.45 \mathrm{E}-09$ & 1 & 1 & $-7.45 \mathrm{E}-09$ & 0.9992 & 0.9992 & $7.45 \mathrm{E}-09$ & 1.0004 & 1.0004 & 0 & 0.5359 & -0.0016 \\
\hline 2440 & 1 & 1 & $7.45 \mathrm{E}-09$ & 1 & 1 & $7.45 \mathrm{E}-09$ & 0.9998 & 0.9998 & 0 & 0.9997 & 0.9997 & 0 & 0.4741 & -0.0016 \\
\hline 2445 & 1 & 1 & 3.73E-09 & 1 & 1 & $7.45 \mathrm{E}-09$ & 0.9998 & 0.9998 & 0 & 0.9997 & 0.9997 & 0 & 0.5175 & -0.0005 \\
\hline 2450 & 1 & 1 & 0 & 1 & 1 & $-1.86 \mathrm{E}-09$ & 1.0013 & 1.0013 & 0 & 1.0021 & 1.0021 & $7.45 \mathrm{E}-09$ & 0.6023 & -0.0015 \\
\hline 2455 & 1 & 1 & $7.45 \mathrm{E}-09$ & 1 & 1 & 0 & 1.0003 & 1.0003 & 0 & 1.0005 & 1.0005 & $-7.45 \mathrm{E}-09$ & 0.5817 & -0.0019 \\
\hline 2460 & 1 & 1 & 0 & 1 & 1 & $-3.73 \mathrm{E}-09$ & 1.0012 & 1.0012 & $7.45 \mathrm{E}-09$ & 1.0008 & 1.0008 & $-7.45 \mathrm{E}-09$ & 0.5385 & -0.0021 \\
\hline 2465 & 1 & 1 & $-7.45 \mathrm{E}-09$ & 1 & 1 & $-3.73 \mathrm{E}-09$ & 1.0028 & 1.0028 & 0 & 1.0013 & 1.0013 & 0 & 0.6499 & -0.0017 \\
\hline 2470 & 1 & 1 & 0 & 1 & 1 & $0.00 E+00$ & 0.9986 & 0.9986 & $7.45 \mathrm{E}-09$ & 0.9972 & 0.9972 & $-7.45 \mathrm{E}-09$ & 0.5853 & -0.0008 \\
\hline 2475 & 1 & 1 & $7.45 \mathrm{E}-09$ & 1 & 1 & $0.00 E+00$ & 1.0000 & 1.0000 & $-7.45 \mathrm{E}-09$ & 1.0003 & 1.0003 & $-7.45 \mathrm{E}-09$ & 0.5630 & -0.0010 \\
\hline 2480 & 1 & 1 & $-7.45 \mathrm{E}-09$ & 1 & 1 & 3.73E-09 & 0.9986 & 0.9986 & 0 & 0.9954 & 0.9954 & $7.45 \mathrm{E}-09$ & 0.6526 & -0.0026 \\
\hline 2490 & 1 & 1 & 0 & 1 & 1 & $7.45 \mathrm{E}-09$ & 1.0008 & 1.0008 & 0 & 0.9978 & 0.9978 & 0 & 0.7966 & -0.0015 \\
\hline 3510 & 1 & 1 & 0 & 1 & 1 & 3.73E-09 & 0.9997 & 0.9997 & 0 & 0.9995 & 0.9995 & 0 & 0.4249 & -0.0012 \\
\hline 3520 & 1 & 1 & $-7.45 \mathrm{E}-09$ & 1 & 1 & $0.00 \mathrm{E}+00$ & 1.0008 & 1.0008 & 0 & 1.0016 & 1.0016 & $7.45 \mathrm{E}-09$ & 0.5453 & -0.0009 \\
\hline 3530 & 1 & 1 & $7.45 \mathrm{E}-09$ & 1 & 1 & $7.45 \mathrm{E}-09$ & 0.9995 & 0.9995 & $7.45 \mathrm{E}-09$ & 0.9995 & 0.9995 & $-7.45 \mathrm{E}-09$ & 0.4462 & -0.0009 \\
\hline 3540 & 1 & 1 & $-7.45 \mathrm{E}-09$ & 1 & 1 & $7.45 \mathrm{E}-09$ & 0.9998 & 0.9998 & $-7.45 \mathrm{E}-09$ & 1.0001 & 1.0001 & 0 & 0.5015 & -0.0013 \\
\hline 3550 & 1 & 1 & $7.45 \mathrm{E}-09$ & 1 & 1 & 0 & 0.9999 & 0.9999 & 0 & 1.0000 & 1.0000 & 0 & 0.5109 & -0.0011 \\
\hline 4610 & 1 & 1 & 0 & 1 & 1 & $0.00 \mathrm{E}+00$ & 1.0005 & 1.0005 & 0 & 0.9979 & 0.9979 & 0 & 0.6644 & -0.0031 \\
\hline 4620 & 1 & 1 & $-7.45 \mathrm{E}-09$ & 1 & 1 & $0.00 \mathrm{E}+00$ & 1.0031 & 1.0031 & $7.45 \mathrm{E}-09$ & 1.0056 & 1.0056 & 0 & 0.7737 & -0.0002 \\
\hline 4630 & 1 & 1 & $-3.73 \mathrm{E}-09$ & 1 & 1 & $-7.45 \mathrm{E}-09$ & 0.9952 & 0.9952 & 0 & 0.9958 & 0.9958 & 0 & 0.6073 & -0.0022 \\
\hline 4640 & 1 & 1 & $-7.45 \mathrm{E}-09$ & 1 & 1 & $-7.45 \mathrm{E}-09$ & 0.9980 & 0.9980 & $7.45 \mathrm{E}-09$ & 0.9921 & 0.9921 & 0 & 0.7333 & -0.0010 \\
\hline 4650 & 1 & 1 & 0 & 1 & 1 & $-3.73 \mathrm{E}-09$ & 1.0012 & 1.0012 & 0 & 1.0009 & 1.0009 & 0 & 0.4713 & -0.0014 \\
\hline 4660 & 1 & 1 & $-7.45 \mathrm{E}-09$ & 1 & 1 & 0 & 0.9990 & 0.9990 & 0 & 0.9986 & 0.9986 & $-7.45 \mathrm{E}-09$ & 0.6325 & -0.0020 \\
\hline 4670 & 1 & 1 & 0 & 1 & 1 & 0 & 1.0026 & 1.0026 & $7.45 \mathrm{E}-09$ & 1.0106 & 1.0106 & 0 & 0.8080 & -0.0015 \\
\hline 4680 & 1 & 1 & 0 & 1 & 1 & 0 & 1.0014 & 1.0014 & 0 & 1.0004 & 1.0004 & $-7.45 \mathrm{E}-09$ & 0.7032 & -0.0015 \\
\hline 4710 & 1 & 1 & $7.45 \mathrm{E}-09$ & 1 & 1 & $-7.45 \mathrm{E}-09$ & 0.9979 & 0.9979 & 0 & 0.9980 & 0.9980 & 0 & 0.5170 & -0.0006 \\
\hline 4720 & 1 & 1 & $-7.45 \mathrm{E}-09$ & 1 & 1 & $-3.73 \mathrm{E}-09$ & 1.0012 & 1.0012 & $7.45 \mathrm{E}-09$ & 1.0028 & 1.0028 & 0 & 0.6095 & -0.0006 \\
\hline 4730 & 1 & 1 & 0 & 1 & 1 & 0 & 1.0014 & 1.0014 & 0 & 1.0015 & 1.0015 & 0 & 0.4866 & -0.0022 \\
\hline 4740 & 1 & 1 & 3.73E-09 & 1 & 1 & 0 & 0.9975 & 0.9975 & $-3.73 \mathrm{E}-09$ & 0.9965 & 0.9965 & $-3.73 \mathrm{E}-09$ & 0.6997 & -0.0003 \\
\hline 4750 & 1 & 1 & 1.12E-08 & 1 & 1 & 3.73E-09 & 1.0025 & 1.0025 & 0 & 0.9970 & 0.9970 & 0 & 0.6341 & $\begin{array}{l}-0.0029 \\
\end{array}$ \\
\hline 4760 & 1 & 1 & 0 & 1 & 1 & $-1.49 \mathrm{E}-08$ & 1.0029 & 1.0029 & 1.49E-08 & 1.0053 & 1.0053 & 0 & 0.8700 & -0.0006 \\
\hline 4810 & 1 & 1 & $7.45 \mathrm{E}-09$ & 1 & 1 & $7.45 \mathrm{E}-09$ & 0.9977 & 0.9977 & 0 & 0.9981 & 0.9981 & 0 & 0.5317 & -0.0007 \\
\hline 4820 & 1 & 1 & $-7.45 \mathrm{E}-09$ & 1 & 1 & $-7.45 \mathrm{E}-09$ & 1.0018 & 1.0018 & 0 & 1.0004 & 1.0004 & $-7.45 \mathrm{E}-09$ & 0.6236 & -0.0034 \\
\hline 4830 & 1 & 1 & $-7.45 \mathrm{E}-09$ & 1 & 1 & $0.00 \mathrm{E}+00$ & 1.0000 & 1.0000 & 0 & 0.9996 & 0.9996 & 0 & 0.3959 & -0.0013 \\
\hline 4840 & 1 & 1 & 0 & 1 & 1 & 3.73E-09 & 1.0022 & 1.0022 & $-7.45 \mathrm{E}-09$ & 1.0037 & 1.0037 & 0 & 0.5745 & -0.0022 \\
\hline 4850 & 1 & 1 & $7.45 \mathrm{E}-09$ & 1 & 1 & $0.00 \mathrm{E}+00$ & 0.9987 & 0.9987 & $-7.45 \mathrm{E}-09$ & 0.9993 & 0.9993 & 0 & 0.5427 & -0.0025 \\
\hline 4860 & 1 & 1 & $-7.45 \mathrm{E}-09$ & 1 & 1 & $0.00 E+00$ & 0.9995 & 0.9995 & 0 & 1.0001 & 1.0001 & 0 & 0.4481 & -0.0012 \\
\hline 4870 & 1 & 1 & $7.45 \mathrm{E}-09$ & 1 & 1 & 0 & 0.9994 & 0.9994 & 0 & 0.9985 & 0.9985 & $-7.45 \mathrm{E}-09$ & 0.5980 & -0.0010 \\
\hline 4880 & 1 & 1 & 0 & 1 & 1 & $0.00 \mathrm{E}+00$ & 1.0016 & 1.0016 & $7.45 \mathrm{E}-09$ & 1.0037 & 1.0037 & 0 & 0.5616 & -0.0008 \\
\hline 5910 & 1 & 1 & $7.45 \mathrm{E}-09$ & 1 & 1 & $7.45 \mathrm{E}-09$ & 0.9998 & 0.9998 & 0 & 0.9990 & 0.9990 & 0 & 0.4349 & -0.0020 \\
\hline 5920 & 1 & 1 & $-7.45 \mathrm{E}-09$ & 1 & 1 & $0.00 \mathrm{E}+00$ & 1.0007 & 1.0007 & $-7.45 \mathrm{E}-09$ & 1.0005 & 1.0005 & $-7.45 \mathrm{E}-09$ & 0.4168 & -0.0015 \\
\hline 5930 & 1 & 1 & 0 & 1 & 1 & $0.00 \mathrm{E}+00$ & 0.9990 & 0.9990 & 0 & 0.9978 & 0.9978 & 0 & 0.5033 & -0.0016 \\
\hline 5940 & 0.9999999 & 1 & 3.73E-09 & 1 & 1 & 0 & 1.0024 & 1.0024 & $7.45 \mathrm{E}-09$ & 1.0020 & 1.0020 & $7.45 \mathrm{E}-09$ & 0.5081 & -0.0029 \\
\hline 5950 & 1 & 1 & $-3.73 \mathrm{E}-09$ & 1 & 1 & 1.12E-08 & 1.0026 & 1.0026 & $7.45 \mathrm{E}-09$ & 1.0045 & 1.0045 & $-7.45 \mathrm{E}-09$ & 0.5574 & -0.0013 \\
\hline 5960 & 1 & 1 & 0 & 1 & 1 & $-7.45 \mathrm{E}-09$ & 0.9976 & 0.9976 & 0 & 0.9977 & 0.9977 & 0 & 0.6184 & -0.0019 \\
\hline 5970 & 1 & 1 & 0 & 1 & 1 & 0 & 0.9998 & 0.9998 & 0 & 1.0059 & 1.0059 & $7.45 \mathrm{E}-09$ & 0.6671 & -0.0030 \\
\hline 5980 & 1 & 1 & $-7.45 \mathrm{E}-09$ & 1 & 1 & $-7.45 \mathrm{E}-09$ & 0.9946 & 0.9946 & $-7.45 \mathrm{E}-09$ & 0.9922 & 0.9922 & 0 & 0.6399 & -0.0007 \\
\hline
\end{tabular}




\section{CHOWHAN \& DUNCAN}

Table A2: 2001 Age and Education Verifications by ER for the Census and SLID

\begin{tabular}{|c|c|c|c|c|c|c|c|c|c|c|c|c|c|c|}
\hline erres25 & SLIDage1 & SLIDage2 & SLIDage3 & SLIDage4 & SLIDage5 & SLIDage6 & Censage1 & Censage2 & Censage3 & Censage 4 & Censage5 & Censage 6 & \begin{tabular}{|l|l} 
Censedu1 & 0 \\
\end{tabular} & Censedu2 \\
\hline 1010 & 1 & 1 & 0 & 1 & 1 & 0 & 0.9986 & 0.9986 & 7.45E-09 & \begin{tabular}{|l|}
0.9987 \\
\end{tabular} & $\begin{array}{l}0.9987 \\
\end{array}$ & 0 & \begin{tabular}{r|}
0.4257 \\
\end{tabular} & $\begin{array}{r}-0.0013 \\
\end{array}$ \\
\hline 1020 & 1 & 1 & $7.45 \mathrm{E}-09$ & 1 & 1 & $-3.73 \mathrm{E}-09$ & 1.0019 & 1.0019 & $-7.45 \mathrm{E}-09$ & 1.0033 & 1.0033 & $7.45 \mathrm{E}-09$ & 0.7350 & -0.0023 \\
\hline 1030 & 1 & 1 & 0 & 1 & 1 & $-7.45 \mathrm{E}-09$ & 1.0012 & 1.0012 & $-7.45 \mathrm{E}-09$ & 1.0008 & 1.0008 & 0 & 0.5638 & -0.0041 \\
\hline 1040 & 1 & 1 & $-3.73 \mathrm{E}-09$ & 1 & 1 & 0 & 1.0001 & 1.0001 & 0 & 0.9990 & 0.9990 & $7.45 \mathrm{E}-09$ & 0.6387 & -0.0041 \\
\hline 1110 & 1 & 1 & 0 & 1 & 1 & $-7.45 \mathrm{E}-09$ & 0.9964 & 0.9964 & $-7.45 \mathrm{E}-09$ & 0.9944 & 0.9944 & 0 & 0.4963 & -0.0029 \\
\hline 1210 & 1 & 1 & 0 & 1 & 1 & $-7.45 \mathrm{E}-09$ & 1.0010 & 1.0010 & $7.45 \mathrm{E}-09$ & 1.0017 & 1.0017 & 0 & 0.5270 & -0.0019 \\
\hline 1220 & 1 & 1 & 3.73E-09 & 1 & 1 & 3.73E-09 & 0.9989 & 0.9989 & 0 & 0.9997 & 0.9997 & 0 & 0.5026 & -0.0026 \\
\hline 1230 & 1 & 1 & 0 & 1 & 1 & 3.73E-09 & 0.9990 & 0.9990 & $-7.45 \mathrm{E}-09$ & 0.9992 & 0.9992 & 3.73E-09 & 0.4937 & -0.0030 \\
\hline 1240 & 1 & 1 & $-3.73 \mathrm{E}-09$ & 1 & 1 & $-3.73 \mathrm{E}-09$ & 1.0010 & 1.0010 & $-3.73 \mathrm{E}-09$ & 0.9975 & 0.9975 & $3.73 \mathrm{E}-09$ & 0.5593 & -0.0008 \\
\hline 1250 & 1 & 1 & 0 & 1 & 1 & $-3.73 \mathrm{E}-09$ & 0.9998 & 0.9998 & $-7.45 \mathrm{E}-09$ & 0.9999 & 0.9999 & $7.45 \mathrm{E}-09$ & 0.3342 & $\begin{array}{l}-0.0020 \\
\end{array}$ \\
\hline 1310 & 1 & 1 & $7.45 \mathrm{E}-09$ & 1 & 1 & $-7.45 \mathrm{E}-09$ & 0.9980 & 0.9980 & 0 & 0.9994 & 0.9994 & $7.45 \mathrm{E}-09$ & 0.6102 & -0.0019 \\
\hline 1320 & 1 & 1 & $-7.45 \mathrm{E}-09$ & 1 & 1 & $7.45 \mathrm{E}-09$ & 1.0002 & 1.0002 & 0 & 0.9988 & 0.9988 & 0 & 0.4938 & -0.0011 \\
\hline 1330 & 1 & 1 & 0 & 1 & 1 & $-3.73 \mathrm{E}-09$ & 0.9959 & 0.9959 & 0 & 0.9943 & 0.9943 & $-7.45 \mathrm{E}-09$ & 0.4994 & -0.0030 \\
\hline 1340 & 1 & 1 & 0 & 1 & 1 & 0 & 0.9991 & 0.9991 & 0 & 0.9991 & 0.9991 & $7.45 \mathrm{E}-09$ & 0.4530 & -0.0017 \\
\hline 1350 & 1 & 1 & $-7.45 \mathrm{E}-09$ & 1 & 1 & $7.45 \mathrm{E}-09$ & 0.9995 & 0.9995 & 0 & 0.9993 & 0.9993 & $7.45 \mathrm{E}-09$ & 0.6180 & -0.0041 \\
\hline 2410 & 1 & 1 & $-3.73 \mathrm{E}-09$ & 1 & 1 & 3.73E-09 & 1.0040 & 1.0040 & 0 & 1.0022 & 1.0022 & $-7.45 \mathrm{E}-09$ & 0.6759 & -0.0058 \\
\hline 2415 & 1 & 1 & 0 & 1 & 1 & 0 & 0.9995 & 0.9995 & 0 & 0.9990 & 0.9990 & 0 & 0.5699 & -0.0113 \\
\hline 2420 & 1 & 1 & 0 & 1 & 1 & 0 & 1.0008 & 1.0008 & $7.45 \mathrm{E}-09$ & 0.9996 & 0.9996 & $7.45 \mathrm{E}-09$ & 0.4307 & -0.0074 \\
\hline 2425 & 1 & 1 & 0 & 1 & 1 & 0 & 0.9996 & 0.9996 & 0 & 0.9995 & 0.9995 & 0 & 0.5394 & -0.0091 \\
\hline 2430 & 1 & 1 & 0 & 1 & 1 & 0 & 0.9989 & 0.9989 & $7.45 \mathrm{E}-09$ & 0.9971 & 0.9971 & $7.45 \mathrm{E}-09$ & 0.5173 & -0.0084 \\
\hline 2433 & 1 & 1 & 3.73E-09 & 1 & 1 & $-1.12 \mathrm{E}-08$ & 1.0006 & 1.0006 & 0 & 1.0014 & 1.0014 & 0 & 0.5702 & -0.0096 \\
\hline 2435 & 1 & 1 & $-7.45 \mathrm{E}-09$ & 1 & 1 & $-3.73 \mathrm{E}-09$ & 1.0005 & 1.0005 & 0 & 1.0000 & 1.0000 & 0 & 0.4800 & -0.0074 \\
\hline 2440 & 1 & 1 & $-3.73 \mathrm{E}-09$ & 1 & 1 & 3.73E-09 & 1.0003 & 1.0003 & 0 & 1.0008 & 1.0008 & $3.73 \mathrm{E}-09$ & 0.4058 & -0.0063 \\
\hline 2445 & 1 & 1 & $1.86 \mathrm{E}-09$ & 1 & 1 & $1.86 \mathrm{E}-09$ & 0.9996 & 0.9996 & 0 & 1.0001 & 1.0001 & 0 & 0.4621 & -0.0068 \\
\hline 2450 & 1 & 1 & 3.73E-09 & 1 & 1 & 0 & 1.0000 & 1.0000 & $7.45 \mathrm{E}-09$ & 1.0023 & 1.0023 & $7.45 \mathrm{E}-09$ & 0.5522 & -0.0071 \\
\hline 2455 & 1 & 1 & $7.45 \mathrm{E}-09$ & 1 & 1 & 0 & 0.9993 & 0.9993 & $7.45 \mathrm{E}-09$ & 1.0004 & 1.0004 & $7.45 \mathrm{E}-09$ & 0.5127 & -0.0063 \\
\hline 2460 & 1 & 1 & 0 & 1 & 1 & 0 & 1.0002 & 1.0002 & $-7.45 \mathrm{E}-09$ & 0.9992 & 0.9992 & 0 & 0.4808 & -0.0077 \\
\hline 2465 & 1 & 1 & 0 & 1 & 1 & $7.45 \mathrm{E}-09$ & 1.0012 & 1.0012 & $-7.45 \mathrm{E}-09$ & 1.0003 & 1.0003 & 0 & 0.6077 & -0.0075 \\
\hline 2470 & 1 & 1 & 0 & 1 & 1 & $-7.45 \mathrm{E}-09$ & 0.9996 & 0.9996 & $7.45 \mathrm{E}-09$ & 0.9996 & 0.9996 & -7.45E-09 & 0.5316 & -0.0075 \\
\hline 2475 & 1 & 1 & $-7.45 \mathrm{E}-09$ & 1 & 1 & $-7.45 \mathrm{E}-09$ & 0.9990 & 0.9990 & $7.45 \mathrm{E}-09$ & 0.9994 & 0.9994 & $7.45 \mathrm{E}-09$ & 0.5064 & -0.0113 \\
\hline 2480 & 1 & 1 & 0 & 1 & 1 & $-7.45 \mathrm{E}-09$ & 0.9983 & 0.9983 & $-7.45 \mathrm{E}-09$ & 0.9991 & 0.9991 & 0 & 0.6162 & -0.0092 \\
\hline 2490 & 1 & 1 & 0 & 1 & 1 & 0 & 0.9897 & 0.9897 & $-7.45 \mathrm{E}-09$ & 0.9902 & 0.9902 & $7.45 \mathrm{E}-09$ & 0.7877 & $\begin{array}{l}-0.0080 \\
\end{array}$ \\
\hline 3510 & 1 & 1 & 3.73E-09 & 1 & 1 & 3.73E-09 & 0.9999 & 0.9999 & $-7.45 \mathrm{E}-09$ & 0.9995 & 0.9995 & $-7.45 \mathrm{E}-09$ & 0.3395 & $\begin{array}{l}-0.0011 \\
\end{array}$ \\
\hline 3515 & 1 & 1 & 0 & 1 & 1 & 0 & 1.0015 & 1.0015 & $7.45 \mathrm{E}-09$ & 1.0021 & 1.0021 & 0 & 0.4547 & -0.0014 \\
\hline 3520 & 1 & 1 & $-7.45 \mathrm{E}-09$ & 1 & 1 & $-7.45 \mathrm{E}-09$ & 1.0014 & 1.0014 & 0 & 1.0011 & 1.0011 & $7.45 \mathrm{E}-09$ & 0.4763 & -0.0015 \\
\hline 3530 & 1 & 1 & 0 & 1 & 1 & $-3.73 \mathrm{E}-09$ & 1.0000 & 1.0000 & 7.45E-09 & 1.0002 & 1.0002 & 0 & 0.3668 & -0.0015 \\
\hline 3540 & 1 & 1 & 0 & 1 & 1 & 0 & 0.9996 & 0.9996 & $7.45 \mathrm{E}-09$ & 0.9985 & 0.9985 & 0 & 0.4263 & -0.0011 \\
\hline 3550 & 1 & 1 & 0 & 1 & 1 & $7.45 \mathrm{E}-09$ & 0.9996 & 0.9996 & 0 & 1.0003 & 1.0003 & 0 & 0.4439 & -0.0012 \\
\hline 3560 & 1 & 1 & $-7.45 \mathrm{E}-09$ & 1 & 1 & 0 & 1.0012 & 1.0012 & $-7.45 \mathrm{E}-09$ & 0.9997 & 0.9997 & $7.45 \mathrm{E}-09$ & 0.4281 & -0.0018 \\
\hline 3570 & 1 & 1 & $7.45 \mathrm{E}-09$ & 1 & 1 & $-3.73 \mathrm{E}-09$ & 1.0000 & 1.0000 & $-7.45 \mathrm{E}-09$ & 1.0006 & 1.0006 & 0 & 0.4608 & -0.0014 \\
\hline 3580 & 1 & 1 & 0 & 1 & 1 & 0 & 1.0020 & 1.0020 & 0 & 1.0019 & 1.0019 & $\begin{array}{l}-7.45 \mathrm{E}-09 \\
\end{array}$ & 0.5108 & -0.0018 \\
\hline 3590 & 1 & 1 & 0 & 1 & 1 & 0 & 0.9997 & 0.9997 & $7.45 \mathrm{E}-09$ & 1.0005 & 1.0005 & $\begin{array}{l}-7.45 \mathrm{E}-09 \\
\end{array}$ & 0.4850 & -0.0024 \\
\hline 3595 & 1 & 1 & 0 & 1 & 1 & $-7.45 \mathrm{E}-09$ & 1.0025 & 1.0025 & $7.45 \mathrm{E}-09$ & 1.0011 & 1.0011 & 0 & 0.4838 & -0.0023 \\
\hline 4610 & 1 & 1 & 7.45E-09 & 1 & 1 & 3.73E-09 & 0.9972 & 0.9972 & $7.45 \mathrm{E}-09$ & 0.9947 & 0.9947 & $-7.45 \mathrm{E}-09$ & 0.6085 & $\begin{array}{l}-0.0028 \\
-10\end{array}$ \\
\hline 4620 & 1 & 1 & $-7.45 \mathrm{E}-09$ & 1 & 1 & 0 & 0.9950 & 0.9950 & 0 & 0.9928 & 0.9928 & 0 & 0.7222 & -0.0042 \\
\hline 4630 & 1 & 1 & $-7.45 \mathrm{E}-09$ & 1 & 1 & $7.45 \mathrm{E}-09$ & 0.9986 & 0.9986 & 0 & 0.9936 & 0.9936 & $-7.45 \mathrm{E}-09$ & 0.5573 & -0.0010 \\
\hline 4640 & 1 & 1 & $3.73 \mathrm{E}-09$ & 1 & 1 & $7.45 \mathrm{E}-09$ & 1.0028 & 1.0028 & $-7.45 \mathrm{E}-09$ & 1.0017 & 1.0017 & $7.45 \mathrm{E}-09$ & 0.6848 & -0.0010 \\
\hline 4650 & 1 & 1 & $-7.45 \mathrm{E}-09$ & 1 & 1 & $-3.73 \mathrm{E}-09$ & 1.0002 & 1.0002 & 0 & 1.0003 & 1.0003 & 0 & 0.4066 & -0.0022 \\
\hline 4660 & 1 & 1 & $-7.45 \mathrm{E}-09$ & 1 & 1 & $-3.73 \mathrm{E}-09$ & 1.0005 & 1.0005 & 0 & 0.9978 & 0.9978 & $-3.73 \mathrm{E}-09$ & 0.5578 & -0.0012 \\
\hline 4670 & 1 & 1 & 3.73E-09 & 1 & 1 & 3.73E-09 & 0.9977 & 0.9977 & 0 & 0.9983 & 0.9983 & $-7.45 \mathrm{E}-09$ & 0.7399 & 0.0005 \\
\hline 4680 & 1 & 1 & 0 & 1 & 1 & $7.45 \mathrm{E}-09$ & 1.0027 & 1.0027 & $7.45 \mathrm{E}-09$ & 1.0017 & 1.0017 & 0 & 0.6551 & -0.0015 \\
\hline 4710 & 1 & 1 & \begin{tabular}{|c|}
$-7.45 \mathrm{E}-09$ \\
\end{tabular} & 1 & 1 & $7.45 \mathrm{E}-09$ & 1.0015 & 1.0015 & 0 & 1.0003 & 1.0003 & $-7.45 \mathrm{E}-09$ & 0.4402 & -0.0014 \\
\hline 4720 & 1 & 1 & 0 & 1 & 1 & $-7.45 \mathrm{E}-09$ & 1.0006 & 1.0006 & 0 & 0.9972 & 0.9972 & $7.45 \mathrm{E}-09$ & 0.5575 & -0.0012 \\
\hline 4730 & 1 & 1 & 0 & 1 & 1 & $-7.45 \mathrm{E}-09$ & 0.9996 & 0.9996 & 0 & 0.9985 & 0.9985 & 0 & 0.4101 & -0.0029 \\
\hline 4740 & 1 & 1 & $-3.73 \mathrm{E}-09$ & 1 & 1 & 0 & 0.9976 & 0.9976 & 0 & 0.9989 & 0.9989 & $-7.45 \mathrm{E}-09$ & 0.6562 & -0.0028 \\
\hline 4750 & 1 & 1 & 7.45E-09 & 1 & 1 & $-7.45 \mathrm{E}-09$ & 0.9999 & 0.9999 & 0 & 1.0013 & 1.0013 & 0 & 0.5572 & -0.0033 \\
\hline 4760 & 1 & 1 & $3.73 \mathrm{E}-09$ & 1 & 1 & $-3.73 \mathrm{E}-09$ & 0.9990 & 0.9990 & $-1.49 \mathrm{E}-08$ & 1.0050 & 1.0050 & $-7.45 \mathrm{E}-09$ & 0.8202 & -0.0024 \\
\hline 4810 & 1 & 1 & 0 & 1 & 1 & $7.45 \mathrm{E}-09$ & 0.9998 & 0.9998 & 0 & 1.0004 & 1.0004 & 0 & 0.4730 & -0.0012 \\
\hline 4820 & 1 & 1 & $-7.45 \mathrm{E}-09$ & 1 & 1 & $7.45 \mathrm{E}-09$ & 0.9970 & 0.9970 & $-7.45 \mathrm{E}-09$ & 0.9999 & 0.9999 & $-7.45 \mathrm{E}-09$ & 0.5297 & -0.0029 \\
\hline 4830 & 1 & 1 & 0 & 1 & 1 & $-7.45 \mathrm{E}-09$ & 0.9995 & 0.9995 & $7.45 \mathrm{E}-09$ & 0.9990 & 0.9990 & 0 & 0.3180 & -0.0022 \\
\hline 4840 & 1 & 1 & $7.45 \mathrm{E}-09$ & 1 & 1 & 0 & 1.0009 & 1.0009 & $7.45 \mathrm{E}-09$ & 1.0021 & 1.0021 & 0 & 0.4995 & -0.0038 \\
\hline 4850 & 1 & 1 & 0 & 1 & 1 & $-7.45 \mathrm{E}-09$ & 1.0010 & 1.0010 & 0 & 0.9986 & 0.9986 & $7.45 \mathrm{E}-09$ & 0.4609 & -0.0029 \\
\hline 4860 & 1 & 1 & $-7.45 \mathrm{E}-09$ & 1 & 1 & $-7.45 \mathrm{E}-09$ & 0.9996 & 0.9996 & $7.45 \mathrm{E}-09$ & 0.9994 & 0.9994 & 0 & 0.3719 & -0.0023 \\
\hline 4870 & 1 & 1 & $7.45 \mathrm{E}-09$ & 1 & 1 & 0 & 0.9994 & 0.9994 & $7.45 \mathrm{E}-09$ & 0.9953 & 0.9953 & $-7.45 \mathrm{E}-09$ & 0.5274 & -0.0029 \\
\hline 4880 & 1 & 1 & $-7.45 \mathrm{E}-09$ & 1 & 1 & $7.45 \mathrm{E}-09$ & 0.9996 & 0.9996 & $-7.45 \mathrm{E}-09$ & 1.0017 & 1.0017 & $7.45 \mathrm{E}-09$ & 0.4807 & -0.0030 \\
\hline 5910 & 1 & 1 & 3.73E-09 & 1 & 1 & 0 & 1.0011 & 1.0011 & $-7.45 \mathrm{E}-09$ & 1.0014 & 1.0014 & 0 & 0.3641 & -0.0025 \\
\hline 5920 & 1 & 1 & $3.73 \mathrm{E}-09$ & 1 & 1 & $-7.45 \mathrm{E}-09$ & 1.0003 & 1.0003 & 0 & 1.0008 & 1.0008 & 0 & 0.3461 & -0.0026 \\
\hline 5930 & 1 & 1 & 0 & 1 & 1 & $-7.45 \mathrm{E}-09$ & 1.0007 & 1.0007 & 0 & 1.0019 & 1.0019 & 0 & 0.4322 & -0.0022 \\
\hline 5940 & 1 & 1 & $7.45 \mathrm{E}-09$ & 1 & 1 & 3.73E-09 & 0.9987 & 0.9987 & 3.73E-09 & 0.9984 & 0.9984 & $-7.45 \mathrm{E}-09$ & 0.4417 & -0.0035 \\
\hline 5950 & 1 & 1 & 0 & 1 & 1 & $-3.73 \mathrm{E}-09$ & 0.9987 & 0.9987 & 0 & 0.9980 & 0.9980 & 0 & 0.4733 & -0.0031 \\
\hline 5960 & 1 & 1 & $-3.73 \mathrm{E}-09$ & 1 & 1 & $-7.45 \mathrm{E}-09$ & 1.0010 & 1.0010 & 7.45E-09 & 1.0028 & 1.0028 & 0 & 0.5590 & -0.0034 \\
\hline 5970 & 1 & 1 & $-7.45 \mathrm{E}-09$ & 1 & 1 & 0 & 0.9976 & 0.9976 & 0 & 0.9980 & 0.9980 & 0 & 0.6221 & -0.0075 \\
\hline 5980 & 1 & 1 & $7.45 \mathrm{E}-09$ & 1 & 1 & $-7.45 \mathrm{E}-09$ & 0.9955 & 0.9955 & $7.45 \mathrm{E}-09$ & 0.9946 & 0.9946 & $7.45 \mathrm{E}-09$ & 0.5680 & -0.0005 \\
\hline
\end{tabular}

